\title{
Ultrasonic shears assistance can shorten the console time in robotic gastrectomy for early gastric cancer
}

\author{
Yoshihiro Kakeji ${ }^{*}{ }^{*}$, Daisuke Kuroda ${ }^{\dagger}$, Tetsu Nakamura, Satoshi Suzuki, Masashi Yamamoto, Shingo Kanaji,
}

Tatsuya Imanishi and Kenichi Tanaka

\begin{abstract}
Background: Robotic gastric surgery has been introduced and is being performed in many Japanese facilities. There are some limitations of devices capable to be used in the robotic arms in the da Vinci Surgical System. We have reviewed our first ten cases with early gastric cancer who underwent robot-assisted gastrectomy and have compared the operative time between cases who underwent the operation only with an electric cautery device and those in whom laparoscopic coagulating shears (LCS) through an assistant port were used.

Findings: We used an electric cautery device only in cases 1-3, and LCS in cases 4-10 except case 9 . The mean operative time was $454 \mathrm{~min}$ in cases where only robotic devices were used and $414 \mathrm{~min}$ in those with LCS assist. The mean console time of $251 \mathrm{~min}$ in those with LCS assist was significantly shorter than that of $306 \mathrm{~min}$ in cases where only robotic devices were used. The number of dissected lymph nodes was satisfactory, and the estimated blood loss was small. Postoperative complications in two cases were slight and transient with short hospital stay.
\end{abstract}

Conclusion: Assistant use of ultrasonic shears is useful to shorten the console time in robotic gastrectomy.

Keywords: Robotic surgery, Gastric cancer, Ultrasonic shears

\section{Findings}

Gastric cancer is the fifth most prevalent neoplasm worldwide [1], and surgery is the most important curative treatment for this malignancy. Various technical special procedures have been tried, and laparoscopic gastrectomy with lymph node dissection has been shown to be not only feasible but also safe, achieving better early postoperative outcomes when compared to conventional open gastrectomy [2-4]. A minimally invasive approach has gained increasing acceptance due to improved postoperative outcomes. Robotic surgery is an emerging technology that allows laparoscopic procedures to be carried out in many surgical situations, and the da Vinci Surgical System has been introduced with encouraging results [5, 6]. Robotic gastrectomy is a feasible and safe procedure

\footnotetext{
*Correspondence: kakeji@med.kobe-u.ac.jp

${ }^{\dagger}$ Yoshihiro Kakeji and Daisuke Kuroda contributed equally to this work Division of Gastrointestinal Surgery, Department of Surgery, Graduate School of Medicine, Kobe University, Kobe, Japan
}

in the hands of experienced laparoscopic surgeons $[7,8]$. In Japan, there has been some limitation in the availability of devices in the da Vinci Surgical System. For example, we cannot use ultrasonic shears which is useful for lymph node dissection in the da Vinci Surgical System. In this article, we analyzed our initial experience in robotic gastrectomy with the da Vinci S Surgical System.

\section{Methods}

Use of the da Vinci S Surgical System at Kobe University, Kobe, Japan began in February 2011. The initial ten consecutive patients with early gastric cancer who were preoperatively diagnosed as cT1N0M0 between February 2011 and April 2012 and subsequently underwent robotassisted gastrectomy (RAG) were used in the analyses. The decision to apply RAG only in patients with early gastric cancer is based on the recommendations of the Japanese treatment guideline for gastric cancer [9] as well as the fact that the oncological safety of minimally 
invasive surgery for advanced gastric cancer remains controversial [3]. The clinicopathologic characteristics, postoperative outcomes, and postoperative morbidities of each case are shown in Table 1. Before surgery, the details of the procedure was explained to all the patients, and appropriately written informed consent was obtained. This clinical study was approved by the Institutional Review Board of Kobe University Hospital (No. 1110) and registered in the University Hospital Medical Information Network (UMIN) Clinical Trials Registry (UMIN-CTR) (UMIN000004181, registered 10 September 2010).

All the operations in the current study were performed by one surgeon (DK) and the same assistants (TN and SS). The da Vinci S Surgical System was used in all procedures except gastro-duodenal or gastro-jejunal anastomoses. All patients underwent distal gasrectomy with D1+ or D2 lymphadenectomy. Figure 1 shows the locations of the trocars. We used one 12-mm trocar for the camera, three 8-mm trocars for the robot arms, and one 12-mm trocar for the surgical assistant. Almost all of the surgical procedures in the abdominal cavity are identical to those of laparoscopic gastrectomy. As ultrasonic shears cannot be used in Japan, we used monopolar curved scissors in the 1st arm, Maryland bipolar forceps in the 2nd arm, and Cadiere forceps in the 3rd arm of the robot. The assistant retracts the stomach or pancreas, operates the stapler, and applies clips. To shorten the console time, the assistant used ultrasonic shears (laparoscopic coagulating shears; LCS) to dissect the omentum and perigastric lymph nodes along the lesser curvature in cases 4-10 except case 9 . The stomach was extracted through a $4 \mathrm{~cm}$ incision at the upper abdomen, and distal gastrectomy was done. Reconstruction by the Billroth-I method was performed through this incision using a $29 \mathrm{~mm}$ circular stapler.
Statistical analysis was performed using the unpaired Student's t test. P values $<0.05$ were considered statistically significant.

\section{Results}

Table 1 shows the clinicopathologic characteristics and operative outcomes of the patients. Although the preoperative clinical staging of all the patients was lower than cT1N0M0, one patient (case 3) had a pT2 lesion. The number of dissected lymph nodes was satisfactory to evaluate pathological metastasis pathologically. The mean operative time was $454 \mathrm{~min}$ in cases where only robotic devices were used, and $414 \mathrm{~min}$ in those with LCS assist. Although the operative time was shorter with LCS assist, there was no statistically significant difference. However, the mean console time of $251 \mathrm{~min}$ in those with LCS assist was significantly shorter than that of 306 min in cases where only robotic devices were used (Fig. 2). The difference between these means console time was $-55.5 \mathrm{~min}, 95 \%$ confidence interval -108.9 to $-2.1 \mathrm{~min}$; $\mathrm{p}=0.0435$. The estimated blood loss was small. Postoperative complications included delayed gastric emptying in case 5 and liver dysfunction in case 6 , both were slight and transient with short hospital stays.

\section{Discussion}

Robot-assisted laparoscopic surgery provides a 3-dimensional view and articulated movement without physiologic tremor. In general, robotic surgery is reported to require a longer operation time than laparoscopic or open conventional surgery. The prolonged operation time is caused by the additional set-up time for the robotic arms, however, this preparatory time period could be shortened [7]. Another reason for delay time may be the restriction on devices that can be used in Japan. Ultrasonic shears is a useful device to dissect the tissue including vessels. It can securely occlude not only arteries but

Table 1 Patients' clinicopathologic characteristics

\begin{tabular}{|c|c|c|c|c|c|c|c|c|c|c|}
\hline Case \# & Age & Sex & BMI & pT & $\mathrm{pN}$ & $\begin{array}{l}\text { Blood loss } \\
\text { (g) }\end{array}$ & $\begin{array}{l}\text { Operative time } \\
\text { (min) }\end{array}$ & $\begin{array}{l}\text { Console time } \\
\text { (min) }\end{array}$ & $\begin{array}{l}\text { Postop. hosp. } \\
\text { stay }\end{array}$ & $\begin{array}{l}\text { Robotic only } \\
\text { or LCS assist }\end{array}$ \\
\hline 1 & 61 & $M$ & 23.5 & pT1a & pNO & 60 & 426 & 275 & 11 & Robotic only \\
\hline 2 & 71 & $M$ & 21.3 & pT1b & pNO & 30 & 408 & 304 & 11 & Robotic only \\
\hline 3 & 57 & F & 26.0 & pT2 & pNO & 60 & 462 & 290 & 10 & Robotic only \\
\hline 4 & 70 & $M$ & 23.5 & pT1a & pNO & 94 & 386 & 225 & 12 & LCS assist \\
\hline 5 & 44 & $\mathrm{~F}$ & 18.0 & pT1b & pNO & 0 & 347 & 204 & 16 & LCS assist \\
\hline 6 & 59 & $F$ & 21.9 & pT1b & pNO & 65 & 404 & 250 & 11 & LCS assist \\
\hline 7 & 50 & $\mathrm{~F}$ & 21.3 & pT1a & pNO & 90 & 441 & 243 & 12 & LCS assist \\
\hline 8 & 68 & $M$ & 26.8 & pT1b & pNO & 155 & 461 & 273 & 11 & LCS assist \\
\hline 9 & 74 & $M$ & 21.4 & pT1b & pNO & 90 & 518 & 355 & 10 & Robotic only \\
\hline 10 & 64 & $M$ & 24.6 & pT1a & pNO & 45 & 444 & 308 & 12 & LCS assist \\
\hline
\end{tabular}




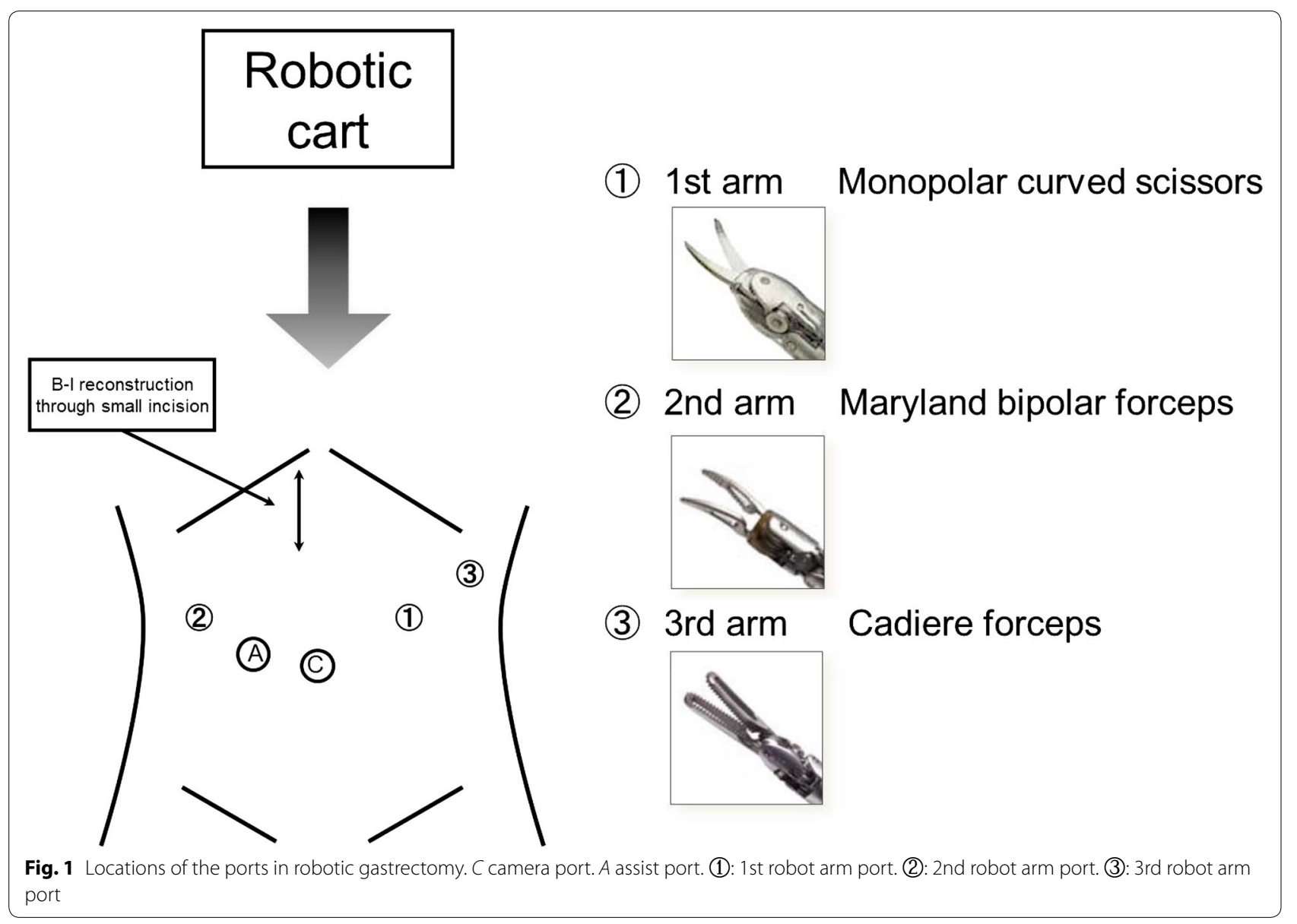

also veins and lymphatic vessels. We used ultrasonic shears mainly in two operative procedures carried out by the assistant through the assist port. The greater omentum was divided and dissected using the ultrasonic shears toward the lower pole of the spleen. After the clipping of the roots of the left gastroepiploic vessels, the division of the omentum was continued downward to the pylorus. This division of the omentum needs less sophisticated manipulation and is quicker. Another procedure is the dissection of perigastric lymph nodes around the lesser curvature up to the esophagogastric junction. It is sometimes difficult to achieve hemostasis by monopolar or bipolar devices. Application of clips takes time because the clips have to be loaded one by one. The ultrasonic shears are effective in sealing the vessels in this field. Thus, the assistant support using ultrasonic shears was significantly effective in shortening the console time (Fig. 2). In case 9, all dissection procedures were performed by robotics only without ultrasonic shears assistance, however, the console time in this case

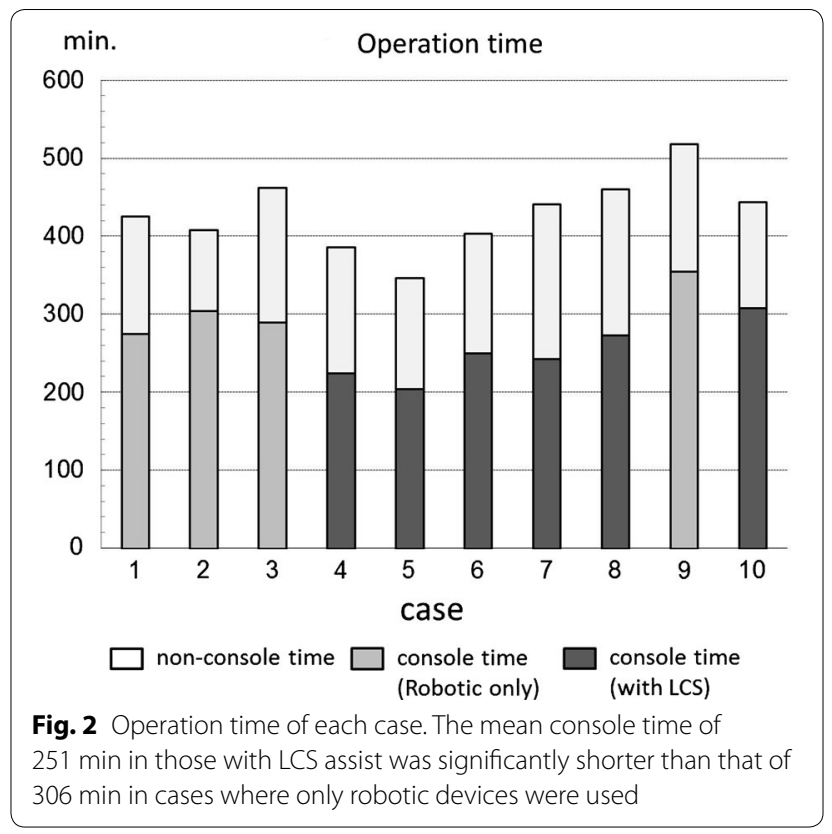


was $355 \mathrm{~min}$. Although we expect the learning effect to shorten the console time, this trial was not successful. Of course, there remains a limitation of statistical analysis because of the small number of cases, a further analysis with more cases will be recommended.

Noshiro et al. [10] reported that robot-assisted distal gastrectomy using electric cautery instruments without ultrasonic-activated devices was feasible and safe with respect to blood loss, lymph node dissection, and complications. If a variety of devices were available for selection, it would increase the possibilities for performing a sophisticated operation.

Ultrasonic energy instruments or a vessel sealer would be helpful for carrying out effective operative procedures in a shorter time. At the present time, assistant use of ultrasonic shears is useful in robotic gastrectomy.

\section{Abbreviations}

RAG: robot-assisted gastrectomy (RAG); LCS: laparoscopic coagulating shears.

\section{Authors' contributions}

YK and DK contributed equally to this work. DK, TN, and SS performed surgery. TN and SS analyzed the data. MY, SK, TI, and KT discussed the analysis. YK and DK designed the study and wrote the manuscript. All authors read and approved the final manuscript.

\section{Acknowledgements}

We thank Takashi Omori from Center for Clinical Research Promotion, Kobe University Hospital, Kobe, Japan, who reviewed statistical methods. This study was conducted without sources of funding.

\section{Compliance with ethical guidelines}

\section{Competing interests}

The authors declare that they have no competing interests.

\section{Financial disclosure}

All authors have indicated they have no financial relationships relevant to this article to disclosure.

Received: 4 May 2015 Accepted: 9 September 2015

Published online: 15 September 2015

\section{References}

1. Bray F, Ren JS, Masuyer E, Ferlay J. Global estimates of cancer prevalence for 27 sites in the adult population in 2008. Int J Cancer J. 2013;132(5):1133-45.

2. Kitano S, Shiraishi N, Uyama I, Sugihara K, Tanigawa N. A multicenter study on oncologic outcome of laparoscopic gastrectomy for early cancer in Japan. Ann Surg. 2007;245(1):68-72.

3. Memon MA, Khan S, Yunus RM, Barr R, Memon B. Meta-analysis of laparoscopic and open distal gastrectomy for gastric carcinoma. Surg Endosc. 2008;22(8):1781-9.

4. Strong VE, Devaud N, Allen PJ, Gonen M, Brennan MF, Coit D. Laparoscopic versus open subtotal gastrectomy for adenocarcinoma: a casecontrol study. Ann Surg Oncol. 2009;16(6):1507-13.

5. Hashizume M, Sugimachi K. Robot-assisted gastric surgery. Surg Clin North Am. 2003;83(6):1429-44.

6. Kakeji Y, Konishi K, leiri S, Yasunaga T, Nakamoto M, Tanoue K, et al. Robotic laparoscopic distal gastrectomy: a comparison of the da Vinci and Zeus systems. Int J Med Robot. 2006;2(4):299-304.

7. Song J, Oh SJ, Kang WH, Hyung WJ, Choi SH, Noh SH. Robot-assisted gastrectomy with lymph node dissection for gastric cancer: lessons learned from an initial 100 consecutive procedures. Ann Surg. 2009;249(6):927-32.

8. Kim MC, Heo GU, Jung GJ. Robotic gastrectomy for gastric cancer: surgical techniques and clinical merits. Surg Endosc. 2010;24(3):610-5.

9. Association Japanese Gastric Cancer. Japanese gastric cancer treatment guidelines 2010 (ver. 3). Gastric Cancer. 2011;14(2):113-23.

10. Noshiro H, Ikeda O, Urata M. Robotically-enhanced surgical anatomy enables surgeons to perform distal gastrectomy for gastric cancer using electric cautery devices alone. Surg Endosc. 2014;28(4):1180-7.

\section{Submit your next manuscript to BioMed Central and take full advantage of:}

- Convenient online submission

- Thorough peer review

- No space constraints or color figure charges

- Immediate publication on acceptance

- Inclusion in PubMed, CAS, Scopus and Google Scholar

- Research which is freely available for redistribution

Submit your manuscript at www.biomedcentral.com/submit
( Biomed Central 